\title{
Analyzing fissuring in boreholes and comparison of different methods
}

\author{
Balázs Vásárhelyi \\ Vásárhelyi \& Co. Ltd, Budapest
}

\author{
László Kovács \\ Kútfej Ltd, Pécs
}

\author{
Ágnes Váró \\ Department of Construction Materials \\ and Engineering Geology, Budapest University \\ of Technology and Economics, Budapest
}

\begin{abstract}
Fissuring of rocks is frequently of greater importance in practical rock engineering operations than the strength of the intact rock. In practice boreholes are usually analyzed by the RQD method. The limitation of this method has been discussed by several authors: for example, for RQD $=0 \%$ [that is, where the joint intercept (distance between joints in the cores) is $10 \mathrm{~cm}$ or less], or RQD $=100 \%$, the RQD provides no information on the core pieces themselves. It does not matter whether the discarded pieces are soil or fresh rock pieces up to $10 \mathrm{~cm}$ in length. In early 2003 , more than 3,000 meter-long boreholes were analyzed in parallel with two different methods: traditional RQD, and Hansági's C (or Kiruna) Method. According to the results, in the case of a very good or very poor core, the $\mathrm{C}$ method shows the jointing patterns better than the widely-used RQD method. The goal of this paper is to present the $\mathrm{C}$ method and its advandages/disadvandages. Linear regression was found for the values between $10 \%<\mathrm{RQD}<90 \%$, but the $C$ value is much more sensitive than the RQD. The classification of the boreholes according to $\mathrm{C}$ method is also presented.
\end{abstract}

Key words: borehole investigation, RQD method, C method, rock mass classification

\section{Introduction}

In geotechnical engineering it is very important to understand the surrounding soil and rock masses. The most useful rock properties are the rock mechanic ones. To obtain these, boreholes should be drilled and core gained from them intact. By getting a sample of the rock in its original state it is possible to examine jointing, infill, weathering, and much more. For the strength of the rock, and to decide on the level of support for a tunnel, understanding of jointing is

\footnotetext{
Addresses: B. Vásárhelyi: H-1126 Budapest, Hollosy u. 23, Hungary, e-mail: vasarhelyib@freemail.hu

Á. Váró: H-1111 Budapest, Stoczek u. 2, Hungary

L. Kovács: H-7631 Pécs, Felső u. 41, Hungary

Received: January 2, 2008; accepted: March 17, 2008
} 
the most relevant need. The RQD and the $\mathrm{C}$ methods allow viewing this property in numerical form.

Following the presentation of the two methods, the comparison will be based upon borehole data from the preliminary exploration of the Radioactive Repository site at Bátaapáti. The data was provided by Mecsekérc Ltd. RQD and $C$ values were calculated for every borehole. All calculations were carried out by the same geotechnical group; therefore any subjective mistake can be regarded as constant.

After several investigations the Central Hungarian Mórágy Basin was chosen as the final disposal facility for low and medium-level radioactive waste. The average height of the hilly land, which is mostly covered by forest, is around 260-280 m aMSL, while the lowest points of the valleys are approximately 160-170 m aMSL.

The stratigraphic sequence of the area is not a complex one, although it has been highly faulted by tectonic activity. The principal rock type is Paleozoic (Carboniferous) granite. The upper part of this unit (more than $10 \mathrm{~m}$ thick) is differentially weathered. The geology of this area is well-known and has been the subject of several publications (e.g. MÁFI 2003). Fissuring of the boreholes was first analyzed and classified by Gálos et al. (2002).

\section{Theoretical background}

The RQD method is one of the most commonly used methods for borehole investigation; the Eurocode 7 also suggests this method for investigation and classification. This value is also used for different rock mass classification systems (f.i. RMR and $\mathrm{Q}$ values, among others). In Hungary, together with the RQDmethod, the C Method is also applied. The latter is not used in international practice, except in Kiruna (Sweden). In this chapter these two methods are presented.

\section{$R Q D$ method - calculation and limitations}

RQD is the most commonly used method for measuring the degree of jointing in rocks. This value is used to calculate the RMR and $Q$ rock mass classifications (Vásárhelyi 2004). In 1964 Deere developed RQD calculating for cores with a diameter larger than $54.7 \mathrm{~mm}(2.15 ")$; later it was converted to allow calculations on the rock surfaces as well. Its proper definition is "the percentage of intact core pieces longer than $100 \mathrm{~mm}$ in the total length of core".

$$
R Q D=\frac{\sum h_{10}}{h_{b}-h_{a}} 100 \quad[\%]
$$

An example is shown in Fig. 1 (Deere 1989). The lengths between two joints should be measured along the axis of the core. By dividing by the entire 
examined length an average value is obtained; therefore it is permissible to give a single number as a result.

Based on RQD results, Eurocode 7-1 categorizes rocks and provides a rock engineering description. The categories are listed in Table 1.

On recommendation of Eurocode 7-1, the fractures caused during the drilling or the extraction of the core should not be counted, since they are not present in the rock mass in its natural state. In the case of slate rock types the measurements must be carried out immediately after drilling in order to obtain a true idea of the degree of jointing in the rock mass. By not letting the core relax any further, it is possible to prevent the

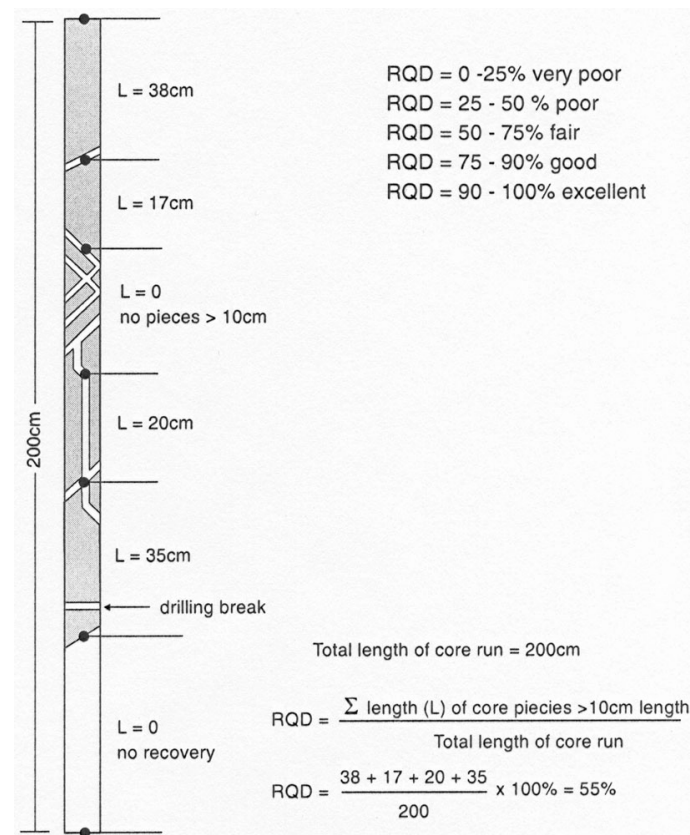

Fig. 1

Calculating RQD (Deere 1989) development of more cracks in the core.

Table 1

Rock mechanical categorization of RQD based on Eurocodee 7-1

\begin{tabular}{lll}
\hline RQD \% & Rock classification based on Eurocode 7-1 & Rock engineering description \\
\hline$>25$ & Very poor & should be regarded as soil \\
$25-50$ & Poor & highly fractured \\
$50-75$ & Good & fractured \\
$75-90$ & Very good & slightly fractured \\
$90-100$ & Excellent & intact \\
\hline
\end{tabular}

One limitation of this method is that no information about the pieces shorter than $10 \mathrm{~cm}$ is obtained. Those parts could be soil-like, full of fractures and therefore appropriately recorded as RQD $=0 \%$, such as the first core sample in Fig. 2. However, parts can be almost $10 \mathrm{~cm}$ long unbroken pieces (second core in Fig. 2), with almost the same strength as other parts of the rock mass, of RQD = $20-30 \%$ or even $100 \%$. The middle two core samples appear the same. The upper one contains only $9 \mathrm{~cm}$-long pieces, while the lower consists of pieces exactly 


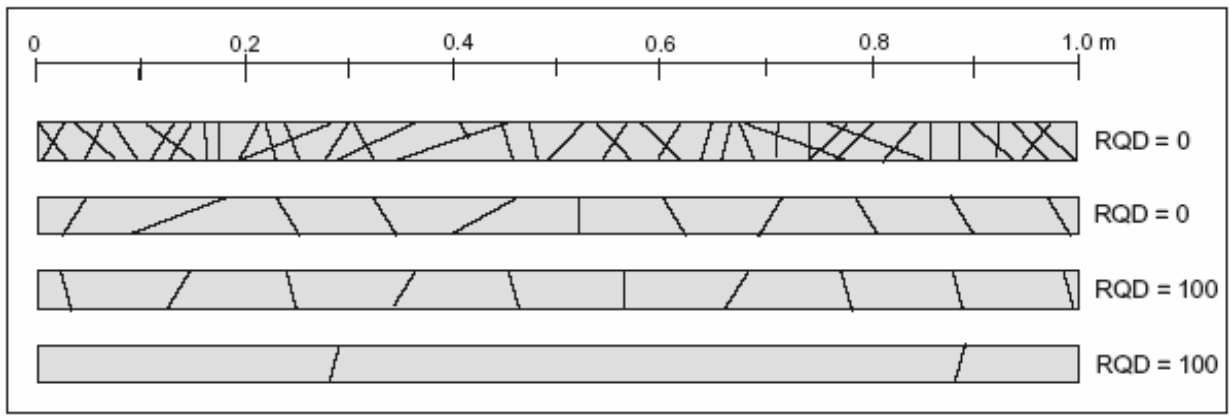

Fig. 2

Examples of minimum and maximum values of RQD for various joints densities along cores (Palmström 2005)

$10 \mathrm{~cm}$ or slightly more in length. The difference between them is that the core consisting of shorter bits is classified as RQD $=0 \%$, while the other one has RQD $=100 \%$. The fourth core sample shows the limitation of RQD at the other extreme. Comparing it to the one with $10 \mathrm{~cm}$-long pieces, it should have much more favorable rock mechanical and water-conductive properties. However, RQD makes no difference between them: both are considered to be intact.

The value of RQD depends on the direction of the borehole in the rock mass, as is the case for every one-dimensional measurement. Therefore it does not give a realistic picture of jointing of the entire volume, but only of the core itself. One cause of this is that Deere does not count the fractures parallel to the axis of the core as a joint. As Fig. 1 shows in the case of a $20 \mathrm{~cm}$-long piece in the middle of the examined section, it is to be considered as an intact piece.

The directional property of the method can cause very different results even for one block. Figure 3 provides an extreme example for this. In the example the rock has three perpendicular joint systems. The joint spacing of two sets is 11 and $15 \mathrm{~cm}$, but the third is only separated by $9 \mathrm{~cm}$. If boreholes are drilled at a right angle to the first two joint sets, RQD will be $100 \%$. In the third direction the intact pieces will be shorter than $10 \mathrm{~cm}$; therefore the RQD result will be $0 \%$.
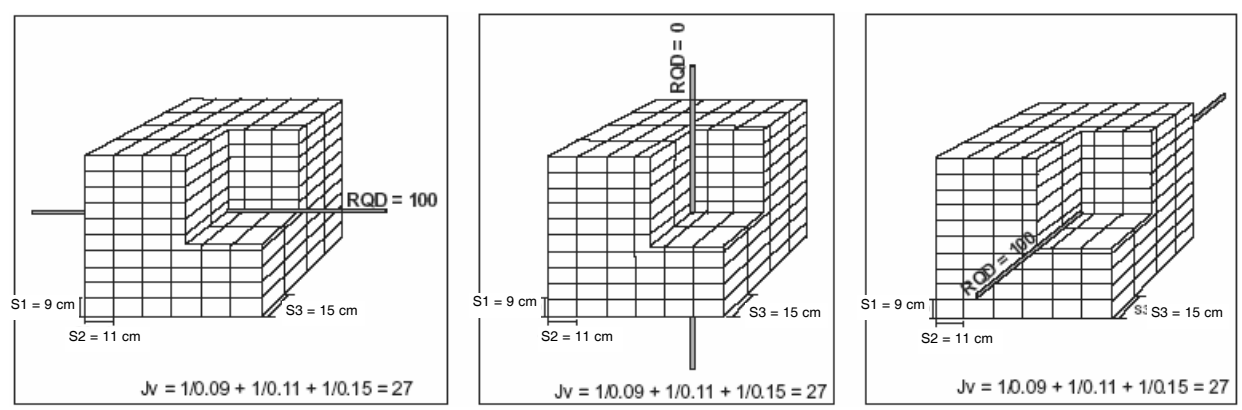

Fig. 3

Example show RQD's directional dependency (Palmström 2005) 


\section{C (or Kiruna) method}

Hansági developed the $\mathrm{C}$ method in 1965 in order to eliminate the restriction of the diameter in calculating RQD. The $\mathrm{C}$ factor can be used for any diameter. Later, Hansági (1974) published his results which were measured in Kiruna (Sweden).

The magnitude of the calculated fissuring factor (C) comprises the arithmetic mean of two coefficients: the $\mathrm{Cp}$ sample factor and the $\mathrm{C}_{\mathrm{m}}$ core length factor.

$$
C=\frac{C_{p}+C_{m}}{2}
$$

The $C_{p}$ factor is similar to RQD. It provides the number of samples that can be seen within the intact pieces of the core, that is, how many times does the full diameter of the core fit to the length of the piece. The sample factor is obtained by multiplying the number of samples that can be gained with the actual diameter and dividing it with the length of the examined section.

$$
C_{p}=\frac{p D}{h_{b}-h_{a}}
$$

$\mathrm{C}_{\mathrm{m}}$ is calculated from the average lengths of the intact pieces from the examined core. While determining the core length factor care should be taken to measure all the pieces. By simply dividing the whole length with the number of fractures we do not get any information of the aperture or the highly fractured zones.

$$
C_{m}=\frac{\bar{m}}{h_{b}-h_{a}}
$$

where:

$$
\bar{m}=\frac{\sum_{i=1}^{n} m_{i}}{n}=\frac{M}{n}
$$

As $C_{m}$ is the ratio of the average length and the full length it is a much smaller value than the $C_{p}$. In this way it indicates the joints of the rock mass. For example $\mathrm{C}_{p}$ can be falsely high if the core consists of about diameter-long intact parts. In this case the $\mathrm{C}_{\mathrm{m}}$ will be much smaller to correct the final value of Kiruna.

The magnitude of the fissuring factor $(\mathrm{C})$ is calculated by means of formulae (2), (3) and (5)

$$
C=\frac{1}{2\left(h_{b}-h_{a}\right)}\left(p D+\frac{M}{n}\right)
$$

When calculating C, it is important to divide the core into sections with similar rock mechanic properties, in order to obtain a clear view of every significant portion of the rock it self. Values for the state of the blocks and the fault zones can be obtained as well. 
The value of Kiruna can vary between 0 and 1 . $C=0$ is the outcome when the intact parts are shorter than the diameter of the core. $\mathrm{C}=1$ is rare; it is possible only when the rock is sound and has no discontinuities in it. The difference between the block of rock and the rock mass is not obvious in this case; the core comes out in one long piece.

\section{Comparing the RQD and the $C$ methods}

The comparison of the two methods is based on the data from the Bátaapáti Repository. All the calculations were made by one person to eliminate differences in subjective mistakes. Another issue is fracturing caused by the drilling/coring methodology, or the lack of experience of the persons performing the work. It was determined that the maximum number of this kind of fractures is only $11 \%$ of all the joints in a core. Thus all possibilities of error are rendered constant and have no great effect upon the values.

Comparison of $C_{p}$ and $R Q D$

Figure 4 shows the similarity of the two factors. Both measure the intact pieces that are longer than a certain length. Clearly a linear relation can be determined between them.

$$
C_{p}=0.0087 R Q D+0.0357
$$

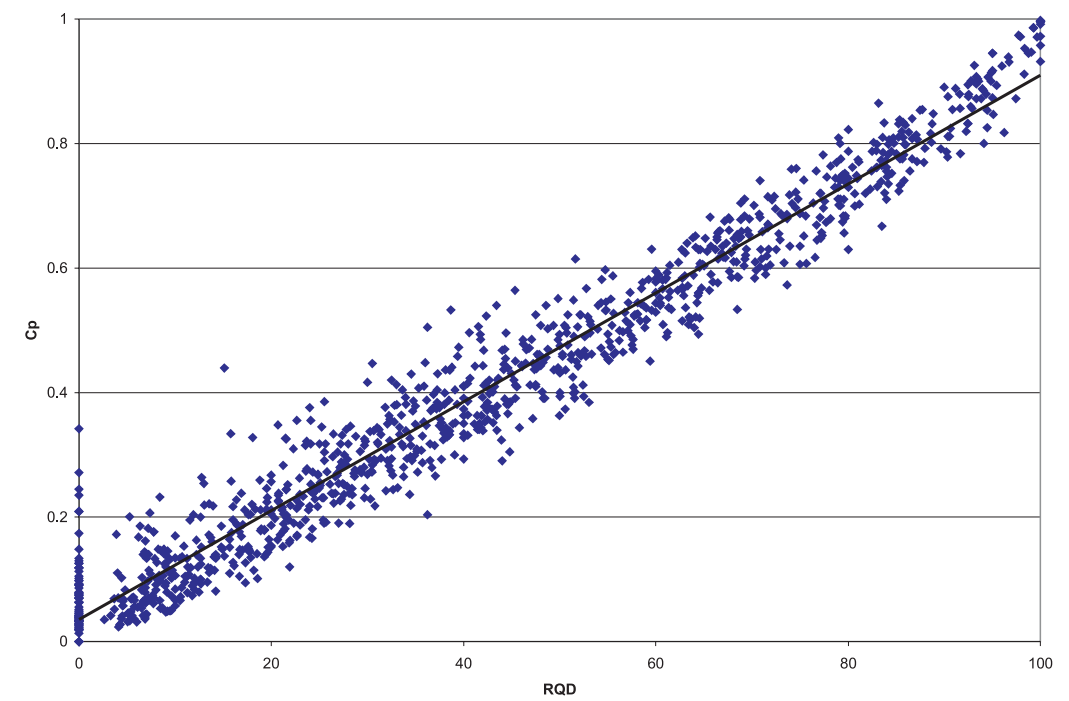

Fig. 4

Relationship between $C_{p}$ and RQD factors 


\section{Comparing $C$ and $R Q D$}

To examine the relationship between two sets of data it is important to know the dimensions of the measurement envelopes. In this way it is possible to see the extreme cases and the standard deviation from the exact relation given between them (see Fig. 5).

The best approximation of the upper curve is linear:

$$
\mathrm{RQD}=222 \mathrm{C}
$$

The lower enveloping curve can be described with a logarithmic equation:

$\mathrm{RQD}=65.28 \ln (\mathrm{C})+98$

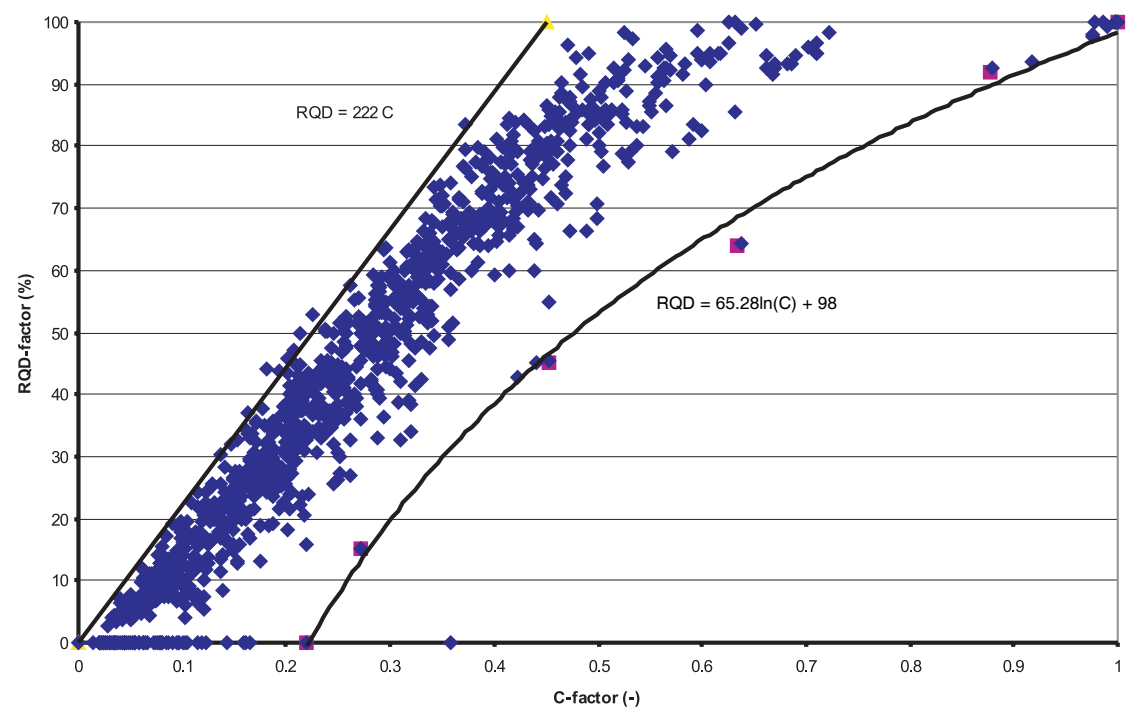

Fig. 5

Enveloping curves of the RQD - C diagram

From the curving lines we can see that the two methods differ considerably at the extreme values. At RQD $=100 \%$ Kiruna varies between 1 and 0.62 , while at RQD $=0 \%$ it varies between 0 and 0.22 . This kind of variation of Kiruna is general in the most jointed parts and the parts that are assumed to be intact by the RQD Method. These cases are when RQD is between 0 and $10 \%$ or between 90 and $100 \%$. Because of the great dispersion no relationship can be given. To obtain a more precise relationship only the values between RQD 10\% and 90\% were examined. Thus a linear relationship between the two methods was obtained (Fig. 6):

$$
\mathrm{RQD}=175.75 \mathrm{C}+2(\%)
$$

Even in the examined area $C$ shows the presence of the joint more precisely than RQD. This is because it takes the average lengths of the intact pieces of the core, which is $\mathrm{C}_{\mathrm{m}^{\prime}}$, into consideration. 


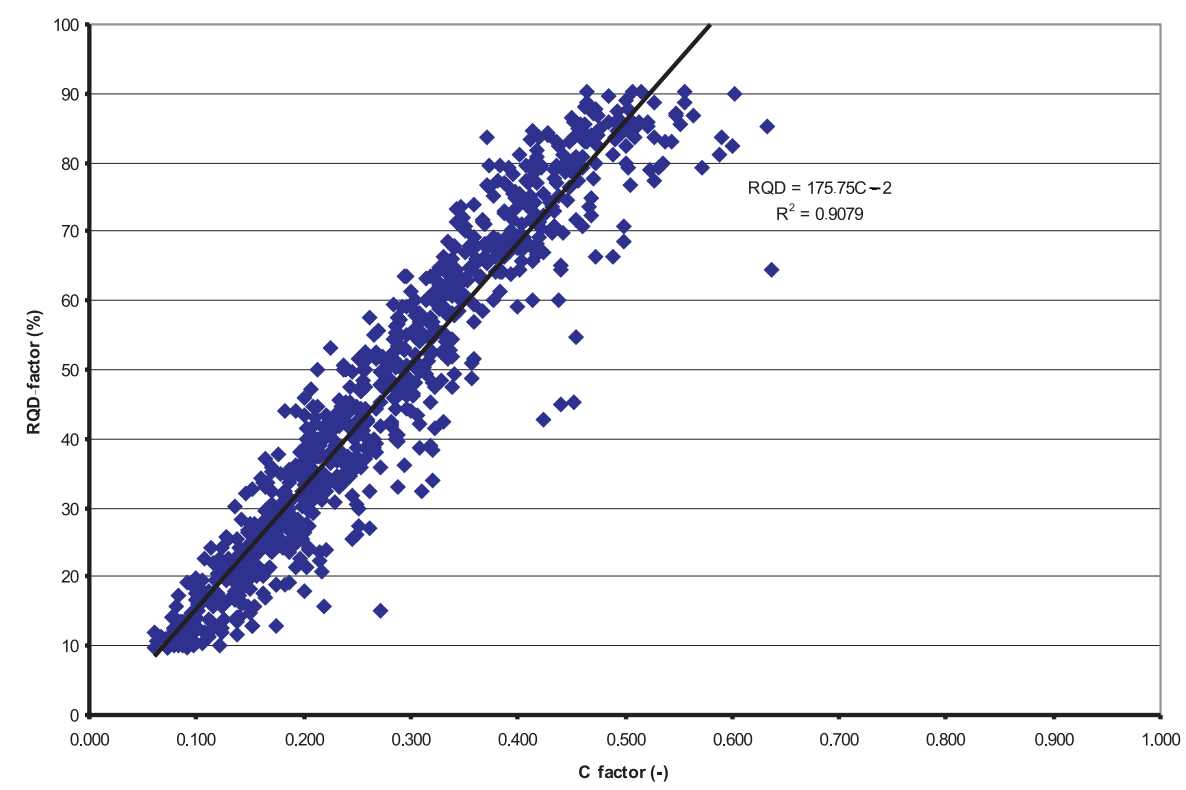

Fig. 6

Relationship between RQD and C values, for cases of RQD between $10 \%$ and $90 \%$

\section{Conclusions}

The RQD and C methods are both simple to use and play an important role in rock mechanical calculation, when designing any kind of underground facility.

While RQD is used much more often - only Sweden and Hungary use the C method - it has more limitations than C. The main advantage of Hansági's C factor is the elimination of the diameter restriction.

It is also possible to apply a classification of units with the $C$ factor, based on practical experience. The following classification (Table 2), suggested after Hansági (1974), offers comparisons between the values from the C and RQD factor methods.

Table 2

Comparison of rock mass classifications using C value and RQD factor (Hansági 1974)

\begin{tabular}{lcc}
\hline Strata characteristics & C value & RQD (\%) \\
\hline Very poor & $0.00-0.15$ & $0-25$ \\
Poor & $0.15-0.30$ & $25-50$ \\
Good & $0.30-0.45$ & $50-75$ \\
Very good & $0.45-0.65$ & $75-90$ \\
Excellent & $0.65-1.00$ & $90-100$ \\
\hline
\end{tabular}


The most important innovation of the $C$ method is the sensitivity at the extremes. The $C$ value reacts more sensitively to changes in the quality of rock mass than the RQD value. With the average core length factor knowledge about the core pieces shorter than $10 \mathrm{~cm}$ is obtained, whether in soil-like state or in intact pieces. In this way fault zones can be more easily found. The other extreme is between RQD $90 \%$ and $100 \%$. With the same data, the C factor provides more information about the state and length of the sound core. It is not necessary to know whether the logged section consists more of smaller (but still a minimum of $10 \mathrm{~cm}$ long) intact parts, or only of a few and much longer pieces.

An important difference between the two methods to be stressed is the elimination of data from the two extremes. Both methods show limitations as far as directional properties are concerned.

The safest means to get to determine the rock strength is to use both methods, and to consider other issues as well, in order to eliminate all limitations of each method or factor.

\section{Acknowledgements}

B. Vásárhelyi acknowledges the financial support for the Bolyai Scholarship and the Hungarian National Research Foundation OTKA D48645 and K60768.

\section{References}

Deere, D.U. 1964: Technical description of rock cores for engineering purposes. - Rock Mech. Engng. Geol., 1, pp. 17-22.

Deere, D.U. 1989: Rock quality designation (RQD) after 20 years. - US Army Corps. Engrs Rep. GL89-1.

EUROCODE 7-1: Geotechnical design - general rules.

Gálos, M., B. Kleb, B. Vásárhelyi 2002: Determining the jointing system of the rock mass properties for the radioactive waste deposit in Hungary. - In: Proc. 9th IAEG Congress, Durban (Eds: van Rooy, J.L., C.A. Jermy), pp. 105-109.

Hansági, I. 1965: Numerical determination of mechanical properties of rock and of rock masses. Int. J. Rock Mech. Min. Sci., 2, pp. 219-223.

Hansági, I. 1974: A method of determining the degree of fissuration of rock. - Int. J. Rock Mech. Min. Sci. Geomech. Abst., 11, pp. 379-388.

MÁFI 2003: Annual Report of the Geological Institute of Hungary. 532 p.

Palmström, A. 2005: Measurements of and correlations between block size and rock quality designation (RQD). - Tunneling \& Underground Space Techn., 20, pp. 362-377.

Vásárhelyi, B. 2004: Kôzettest-osztályozási módszerek összefoglalása (Rock mass classification systems). - Földtani Közlöny, 134/1, pp. 109-129. 